\title{
The vertical structure of cloud radiative heating over the Indian subcontinent during summer monsoon
}

\author{
E. Johansson ${ }^{1}$, A. Devasthale ${ }^{1}$, T. L'Ecuyer ${ }^{2}$, A. M. L. Ekman ${ }^{3,4}$, and M. Tjernström ${ }^{3,4}$ \\ ${ }^{1}$ Atmospheric Remote Sensing, Research and development department, Swedish Meteorological and Hydrological Institute \\ (SMHI), Norrköping, Sweden \\ ${ }^{2}$ Department of Atmospheric and Oceanic Sciences, University of Wisconsin-Madison, Madison, USA \\ ${ }^{3}$ Department of Meteorology, Stockholm University (MISU), Stockholm, Sweden \\ ${ }^{4}$ Bolin Center for Climate Research, Stockholm University, Stockholm, Sweden \\ Correspondence to: E. Johansson (erik.johansson@smhi.se)
}

Received: 14 January 2015 - Published in Atmos. Chem. Phys. Discuss.: 25 February 2015

Revised: 21 September 2015 - Accepted: 26 September 2015 - Published: 21 October 2015

\begin{abstract}
Clouds forming during the summer monsoon over the Indian subcontinent affect its evolution through their radiative impact as well as the release of latent heat. While the latter is previously studied to some extent, comparatively little is known about the radiative impact of different cloud types and the vertical structure of their radiative heating/cooling effects. Therefore, the main aim of this study is to partly fill this knowledge gap by investigating and documenting the vertical distributions of the different cloud types associated with the Indian monsoon and their radiative heating/cooling using the active radar and lidar sensors onboard CloudSat and CALIPSO. The intraseasonal evolution of clouds from May to October is also investigated to understand pre-to-post monsoon transitioning of their radiative heating/cooling effects.

The vertical structure of cloud radiative heating (CRH) follows the northward migration and retreat of the monsoon from May to October. Throughout this time period, stratiform clouds radiatively warm the middle troposphere and cool the upper troposphere by more than $\pm 0.2 \mathrm{~K} \mathrm{day}^{-1}$ (after weighing by cloud fraction), with the largest impacts observed in June, July and August. During these months, the fraction of high thin cloud remains high in the tropical tropopause layer (TTL). Deep convective towers cause considerable radiative warming in the middle and upper troposphere, but strongly cool the base and inside of the TTL. This cooling is stronger during active $\left(-1.23 \mathrm{~K} \mathrm{day}^{-1}\right)$ monsoon periods compared to break periods $\left(-0.36 \mathrm{~K} \mathrm{day}^{-1}\right)$. The contrasting radiative warming effect of high clouds in the TTL is twice as large
\end{abstract}

during active periods than in break periods. These results highlight the increasing importance of $\mathrm{CRH}$ with altitude, especially in the TTL.

Stratiform (made up of alto- and nimbostratus clouds) and deep convection clouds radiatively cool the surface by approximately -100 and $-400 \mathrm{~W} \mathrm{~m}^{-2}$ respectively while warming the atmosphere radiatively by about 40 to $150 \mathrm{~W} \mathrm{~m}^{-2}$. While the cooling at the surface induced by deep convection and stratiform clouds is largest during active periods of monsoon, the importance of stratiform clouds further increases during break periods. The contrasting CREs (cloud radiative effects) in the atmosphere and at surface, and during active and break periods, should have direct implications for the monsoonal circulation.

\section{Introduction}

Clouds cover about $70 \%$ of the Earth's surface area (Stubenrauch et al., 2012) and are a key component of the Earth's energy and water cycle. They have multiple influences on the state of the atmosphere, occurring over a wide range of spatio-temporal scales. From an energy perspective, apart from modulating the net surface radiation, clouds substantially influence the diabatic heat budget of the atmosphere through radiative heating/cooling and latent heat release (Fueglistaler et al., 2009a; L'Ecuyer and McGarragh, 2010). Therefore, clouds are an important part of the landocean-atmosphere coupling mechanisms that regulate atmo- 
spheric circulation. The World Climate Research Program (WCRP) has identified the understanding of clouds and their coupling with atmospheric circulation as one of their Grand Challenges (http://www.wcrp-climate.org/index.php/ grand-challenges/gc-clouds). Quantifying the role of clouds for the energy budget on shorter timescales (days to months) and the implications and feedbacks on climate on longer timescales (years) is critical to address this challenge.

A variety of clouds are observed over the Indian subcontinent during summer months every year, interacting with radiation and affecting the atmosphere and monsoonal circulation. These clouds can be divided into different types: stratiform, convective, and high clouds, where the last type includes thin and anvil cirrus at various stages of their life cycle (formed in situ and remnants from convection). Each of these cloud types plays a unique role during monsoon months as discussed below via their radiative heating/cooling potential and latent heat release within the atmosphere as well as via their net radiative effects on the surface and at the top of the atmosphere. While covering large areas, stratiform clouds are responsible for a substantial amount of rainfall and produce latent heating dominating the low- to mid-level parts of the troposphere over the Indian subcontinent (Stano et al., 2002; Basanta Samala and Krishnan, 2007; Houze et al., 2007; Dey Choudhury and Krishnan, 2011; Krishnan et al., 2011; Romatschke and Houze Jr., 2011). Deep convective towers produce strong latent heating, but this is more localized and intermittent. The latent heating generated by stratiform and convective clouds is large enough that, in combination with the radiative heating (CRH) generated by the same clouds, it should be able to sustain monsoonal circulation throughout the summer months (Webster et al., 1998).

While latent heating dominates the lower and midtroposphere, CRH becomes increasingly important with altitude. Two cloud types, deep convection and isolated ice clouds (esp. thin cirrus), are of paramount importance in the upper troposphere and lower stratosphere (UTLS), especially in the tropical tropopause layer (TTL) (Feldman et al., 2008; Fueglistaler et al., 2009a; Fueglistaler and Fu, 2006; Randel and Jensen, 2013; Yang et al., 2010; Tzella and Legras, 2011). Although the long-term net effect of deep convective clouds may be to dehydrate the TTL, these clouds occasionally penetrate and moisten the TTL. The radiative impact of thin cirrus clouds in the UTLS region, especially in the TTL, is widely recognized. For example, it is considered that the large-scale uplift of air masses in the Brewer-Dobson circulation is facilitated in the TTL by the presence of thin cirrus. The net heating effect of these thin clouds could enhance the upwelling and transport of air masses across the TTL (producing enough slow ascent to dehydrate the TTL).

In spite of their seminal role in influencing the atmospheric dynamics during summer monsoon, the individual contributions from latent and radiative heating components to the total diabatic heating have not been quantified hitherto over the Indian subcontinent. The role of latent heating has been previously investigated in a few studies to some extent $(\mathrm{Zu}-$ luaga et al., 2010, and references therein), but the radiative component of heating has received very little attention so far due to a lack of suitable observations. This is the knowledge gap that the present study aims to address over the Indian subcontinent by documenting radiative heating/cooling contributions from different cloud types and their intraseasonal evolution from May to October.

As a result of limited knowledge of radiative heating/cooling potential of different cloud types, currently there exist significant differences in CRH estimates amongst various reanalyses (Ling and Zhang, 2013; Wright and Fueglistaler, 2013), as well as between models and observations (McFarlane et al., 2007). Due to the ability to resolve the detailed vertical structure of clouds in combination with the possibility to precisely delineate different types of cloudy layers, the A-Train constellation of satellites is an extremely useful source of information to improve our understanding of the radiative heating/cooling effects (L'Ecuyer and Jiang, 2010; Haynes et al., 2011; Henderson et al., 2013). Especially the combination of data from CloudSat and CALIPSO satellites can address the inherent limitations of passive imagers that can only provide a 2-D image of clouds. Therefore we here exploit the state-of-the-art estimates of CRH for the years 2006-2011 derived from the application of broadband radiative transfer calculations to cloud and aerosol information obtained from space-based lidar and radar observations (L'Ecuyer et al., 2008; Henderson et al., 2013) to answer the following scientific questions:

1. How does the vertical distribution of CRH evolve over the Indian continent during pre-monsoon, monsoon and post-monsoon seasons?

2. What is the absolute contribution of different clouds types to the total CRH?

3. How do active and break periods of monsoon affect the distribution of CRH?

4. What are the net radiative effects of different cloud types at surface?

The first three questions are discussed with a specific focus on the UTLS region. Addressing these questions is the first step towards quantifying the role of cloud radiative heating/cooling in shaping the atmospheric dynamics during monsoon.

\section{Data and methodology}

For the present study we use calculations of radiative heating/cooling profiles from the CloudSat 2B-FLXHR-LIDAR product between 2006 and 2010. This data set exploits the synergy from sensors onboard the A-Train convoy of 
satellites, especially from the Cloud Profiling Radar onboard CloudSat and the Cloud-Aerosol Lidar with Orthogonal Polarization onboard Cloud-Aerosol Lidar and Infrared Pathfinder Satellite Observations (CALIPSO) satellite (L'Ecuyer et al., 2008; Henderson et al., 2013). A detailed description of the CloudSat 2B-FLXHR-LIDAR algorithm can be found in the Process Description and Interface Control Document (Henderson et al., 2011).

The calculations use a broadband two-stream planeparallel doubling-adding radiative transfer model consisting of six shortwave and twelve longwave bands. For each atmospheric layer, the information on state variables (temperature, humidity, ozone etc) is obtained from ECMWF (ERAInterim), and cloud and aerosol properties are retrieved from the various CloudSat and CALIPSO products. For example, 2B-GEOPROF-LIDAR product (Mace et al., 2008) provides time and location of cloud layers, while $2 \mathrm{~B}-\mathrm{CWC}$ (Cloud Water Content), 2B-TAU (Cloud optical depth) and 2B-PRECIP-COLUMN (Precipitation flag and profiles) provide cloud microphysical information. Aerosol profiling is provided by CALIPSO and their optical properties are taken from D'Almeida et al. (1991) and WCP-55 (1983). The mixing ratios of methane, carbon dioxide and nitrous oxide are held uniform at 1.6, 360.0 and 0.28 ppmv respectively. Additional information on surface reflection properties and zenith angles is taken from the Moderate Resolution Imaging Spectroradiometer (MODIS) and Advanced Microwave Scanning Radiometer (AMSR-E)-based CloudSat AN-ALBEDO, AMSR-AUX and MODIS-AUX products.

At each location, atmospheric profiles from CloudSat are available only at certain times of the day, hence, the shortwave heating rates are normalized by a factor that takes into account the diurnal variation of insolation (an example is shown in Fig. 1). The normalization factor is computed as follows.

First, to calculate the flux density of solar radiation $(Q)$ a combination of the inverse-square law and Lambert's cosine law is used:

$Q=S_{o} \frac{R_{o}^{2}}{R_{\mathrm{E}}^{2}} \cos \Theta$ when $\cos \Theta>0$

$Q=0$ when $\cos \Theta \leq 0$,

where $S_{O}$ is the solar constant, $R_{O}$ is the mean distance to the sun from earth while $R_{\mathrm{E}}$ is the actual distance between Earth and Sun. $\Theta$ is the solar zenith angel and can be defined using the spherical law of cosines:

$\cos (\Theta)=\sin (\phi) \sin (\delta)+\cos (\phi) \cos (\delta) \cos (h)$,

where $\Phi$ is the latitude, $\delta$ is the solar declination and $h$ is the hour angle. To calculate the mean flux density of solar radiation for 1 day, the average of $Q$ over one rotation is calculated. During one rotation $h$ progresses from $\pi$ to $-\pi$ :

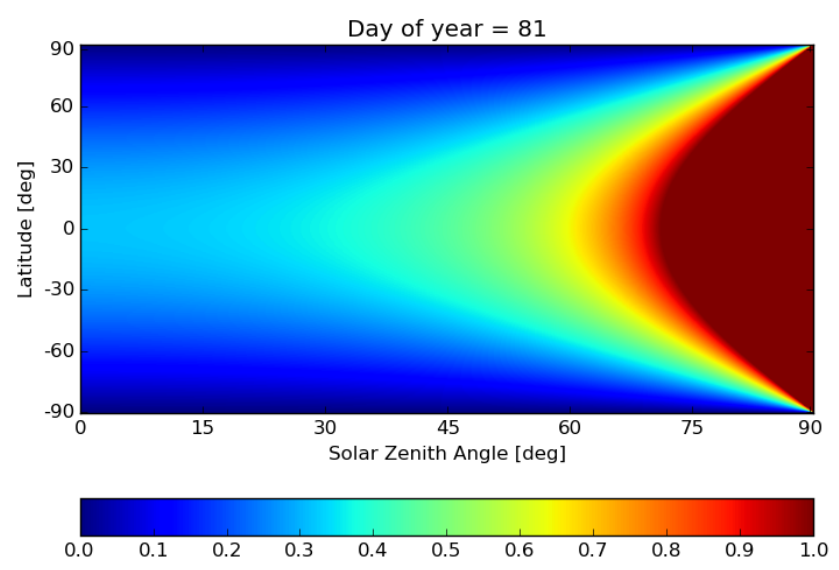

Figure 1. An example of normalization factor for day 81 of a year as a function of latitude and solar zenith angle.

$\bar{Q}^{\text {day }}=-\frac{1}{2 \pi} \int_{\pi}^{-\pi} Q \mathrm{~d} h$.

Solving Eq. (3) gives

$\bar{Q}^{\text {day }}=$

$$
\frac{S_{o}}{\pi} \frac{R_{o}^{2}}{R_{\mathrm{E}}^{2}}\left[h_{o} \sin (\phi) \sin (\delta)+\cos (\phi) \cos (\delta) \sin \left(h_{o}\right)\right],
$$

where $h_{0}$ is the hour angle when $Q$ becomes positive, i.e. when $\Theta=\frac{1}{2} \pi$.

The normalization factor is then,

$$
\begin{aligned}
f & =\frac{\bar{Q}^{\text {day }}}{Q} \\
f & =\frac{h_{o} \sin (\phi) \sin (\delta)+\cos (\phi) \cos (\delta) \sin \left(h_{o}\right)}{\pi \cos \Theta} \text { factor } \\
& =\frac{h_{o} \sin (\phi) \sin (\delta)+\cos (\phi) \cos (\delta) \sin \left(h_{o}\right)}{\pi \cos \Theta}
\end{aligned}
$$

Then for each cloud type studied here, the CRH is calculated as:

$$
\begin{aligned}
\mathrm{CRH} & =\left(\left(f \cdot \mathrm{SWHR}_{\text {cloudy }}+\mathrm{LWHR}_{\text {cloudy }}\right)\right. \\
& \left.-\left(f \cdot \mathrm{SWHR}_{\text {clear }}+\mathrm{LWHR}_{\text {clear }}\right)\right) \cdot \mathrm{CF},
\end{aligned}
$$

where SWHR and LWHR are shortwave and longwave heating rates, respectively, normalized by the factor $\mathrm{f}$ mentioned above. CF is the absolute fraction of cloud type in question. By weighing with cloud fraction, we get the absolute contribution of that particular cloud type. For each height bin, $\mathrm{CF}$ is computed by dividing the number of cloudy pixels of a particular cloud type by the total number of pixels, cloudy and clear. 


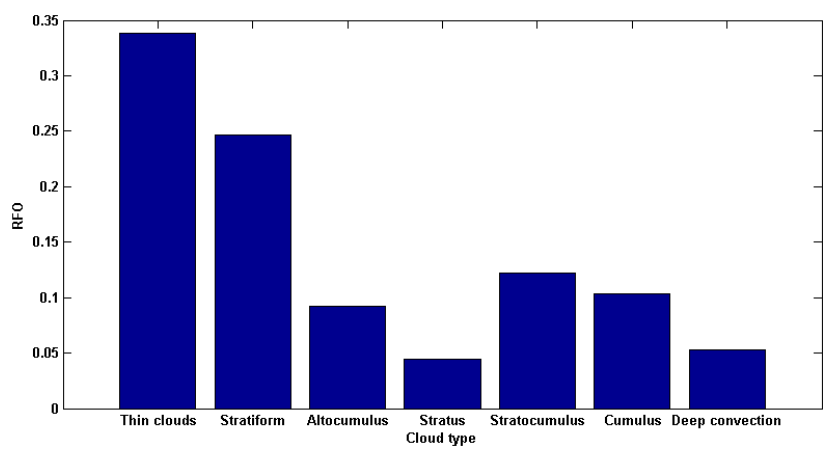

Figure 2. The relative frequency of occurrence (RFO) of different cloud types over the Indian subcontinent based on 2B-CLDCLASSLIDAR product for 2006-2010.

We used the 2B-FLXHR-LIDAR data from August 2006 to October 2010 and for May through October, since the focus of the study is on summer monsoon and pre- and postmonsoon periods. The study investigates three cloud types: high clouds (cirrus), deep convective clouds and a combination of alto- and nimbostratus (referred to as stratiform clouds). These cloud types are selected for several reasons. First, collectively, their relative frequency of occurrence is from 65 to $85 \%$ depending on location and month (Fig. 2). Second, these cloud types are expected to have the largest impact on the UTLS region (Dessler and Sherwood, 2004; Gettelman et al., 2002; Rossow and Pearl, 2007), which is the main focus of the present study. We used collocated 2BCLDCLASS-LIDAR product to obtain information on selected cloud types. A combination of threshold and fuzzy logic based approaches are used to classify cloud types in the 2B-CLADCLASS-LIDAR product (Wang et al., 2013). A neural network, that is trained based on contextual, spectral and geometrical properties of cloud types, is used in the fuzzy classifier. The classifier first uses combined radar and lidar data to find cloud clusters according to their persistence in horizontal and vertical dimensions. Then cloud physical properties such as temperature and height are examined for cloud clusters. Finally, cluster mean properties and spatial inhomogeneities in physical properties are sent to fuzzy classifier to categorize detected cluster into one cloud type and to assign confidence level. Further details of the cloud type algorithm can be seen in Wang et al. (2013).

Figure 3 shows the study area and three zones selected for investigation. This selection is based on previous studies of the description of cloud variability over the study area (Devasthale and Grassl, 2009; Devasthale and Fueglistaler, 2010) and on the distribution of precipitation. The first zone $\left(65-75^{\circ} \mathrm{E}\right.$, denoted Z1) covers the western equatorial Indian Ocean and Arabian Sea, the parts of the subcontinent that experience the first monsoon showers and show largest variability in convective activity during active/break periods of monsoon, and the southwestern coast of India that experi-
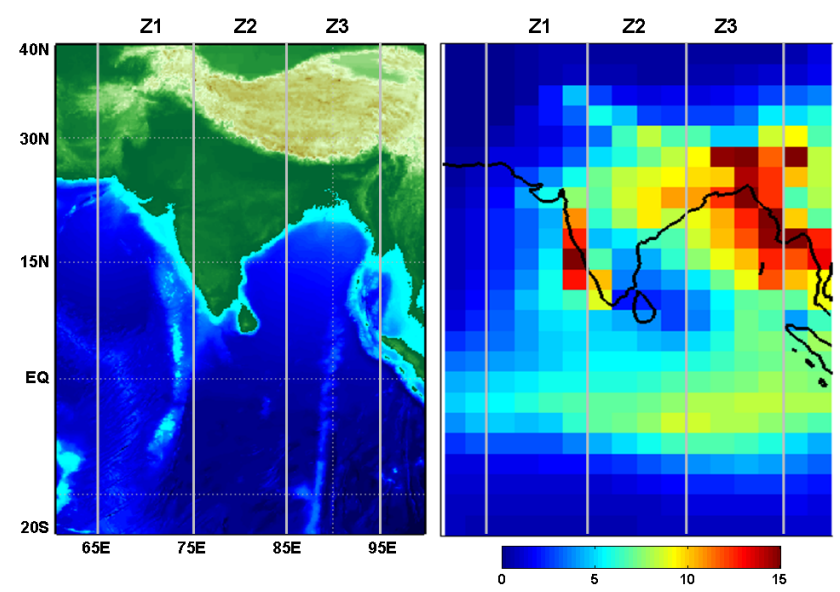

Figure 3. The study area and three selected zones (left panel) and climatological distribution of rainfall $\left(\mathrm{mm}\right.$ day $^{-1}$, right panel) for summer monsoon (JJAS) obtained from the Global Precipitation Climatology Project Version 2.2 monthly data (Huffman et al., 2009).

ences a very high amount of rainfall (Fig. 3b). The second zone $\left(75-85^{\circ} \mathrm{E}, \mathrm{Z2}\right)$ covers central and southern Indian regions, while the third zone $\left(85-95^{\circ} \mathrm{E}, \mathrm{Z3}\right)$ covers the Bay of Bengal, northeastern parts of India and the Tibetan Plateau. All zones are subjected to intense convection over the subcontinent, and also receive high amount of rainfall during the monsoon season (Fig. 3b).

\section{Results and discussions}

\subsection{Vertical distribution of clouds over the Indian subcontinent}

The majority of clouds over the subcontinent are present between 5 and $16 \mathrm{~km}$, (Fig. 4) thus most likely consisting of ice. The vertical distribution of individual cloud types is shown in Figs. S1 to S3 in the Supplement. In May, all cloud types are prevalent around the equatorial Indian Ocean, but their progression towards continental India in response to the strengthening of the monsoonal circulation in subsequent months is also clearly visible. The highest and the most vigorous clouds are observed in Z3 over the Bay of Bengal and the northeastern Indian regions. The vertical cloud fraction, defined as the fraction of number of cloudy pixels in latitudeheight bins divided by total number of pixels, peaks during June and July over most of the continent. In August, the cloud fraction is still high over northern India. At the end of August and in September, cloud fraction decreases sharply as the monsoon circulation weakens. The lowest cloud fraction is thus observed during September. In October, the vigorous band of cloudiness is shifted to lower latitudes, even south of the equator. The onset of the northeast monsoon causes increased cloudiness in October compared to September. 


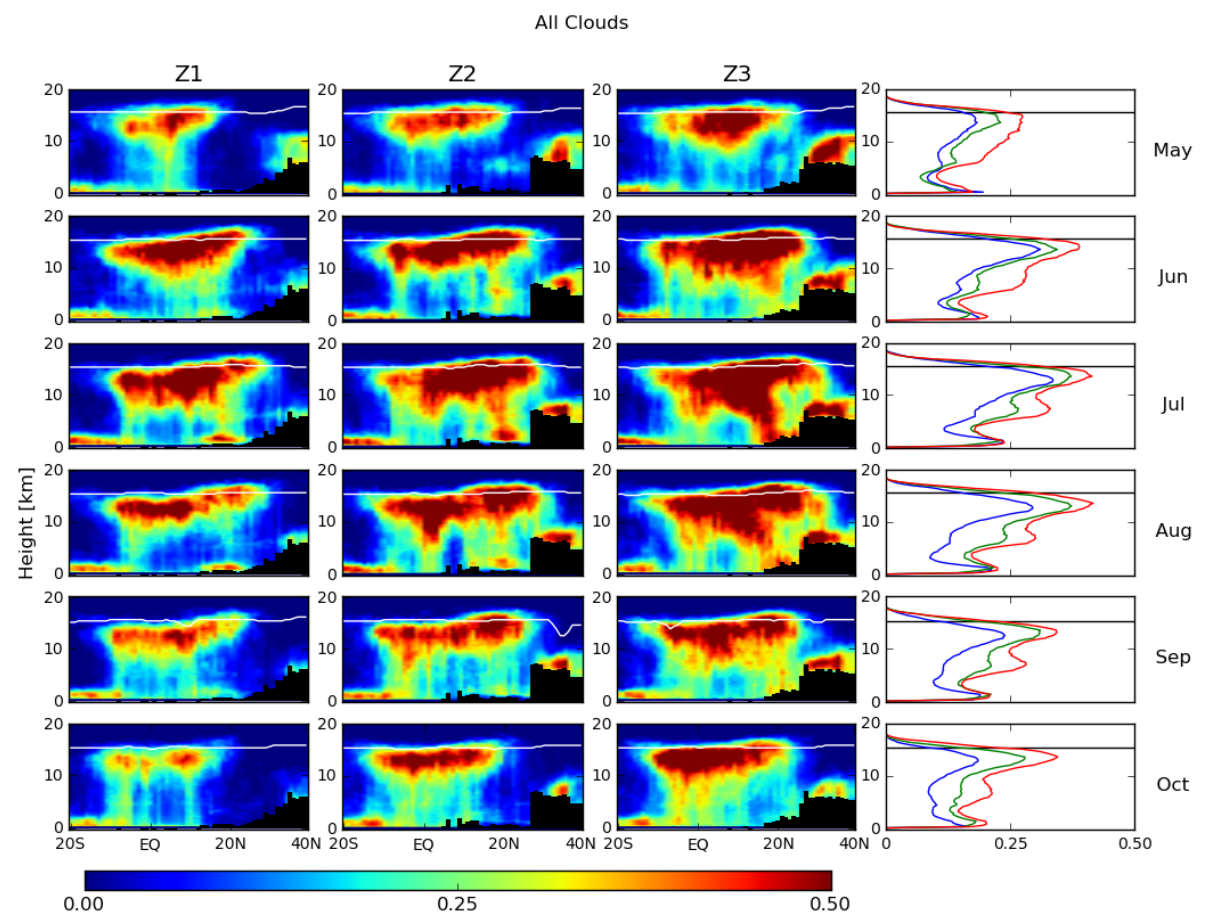

Figure 4. The vertical cloud fraction over the selected three zones (cf. Fig. 3) for each month from May to October. The white line represents the level of net clear-sky zero radiative heating as proxy for the base of the TTL. The rightmost column shows vertical distribution of clouds averaged over the entire zone for Z1 (blue), Z2 (green) and Z3 (red).

Although the intraseasonal migration of clouds during the summer monsoon has been studied before in more general terms (e.g. Devasthale and Grassl, 2009; Devasthale and Fueglistaler, 2010), the detailed vertical structure obtained from the data displayed in Fig. 4 provides additional insights. For example, the intraseasonal variability of clouds above the base of the TTL, here represented by the level of clear-sky zero radiative heating (LZRH) and shown as a white line in Fig. 4, provides an indication of the potential role of clouds in providing water vapor to the UTLS and also affecting other UTLS processes. The vertical cloud fraction above LZRH surprisingly remains very high from June through August and clouds clearly penetrate well into the TTL. Figure 4 further reveals differences in cloudiness and cloud height over the Tibetan Plateau compared to the southern slopes of Himalayas and the Bay of Bengal. It is evident in $\mathrm{Z} 2$ and $\mathrm{Z} 3$, including parts of the Tibetan Plateau $\left(28-40^{\circ} \mathrm{N}\right)$, that the majority of clouds remain below LZRH here, in contrast to the Bay of Bengal and the southern slopes of Himalayas where they are prevalent well into the TTL.

Figure 5 shows the probability density functions (PDF) of liquid and ice water paths, based on 2B-CWC-RVOD data set, of the three cloud types selected for further analysis in the present study. High clouds, by our definition, do not contain liquid water, while all three types contain ice. In the case of high clouds, the PDF of ice water path follows a sharp exponential distribution, while for stratiform clouds, the distribu-
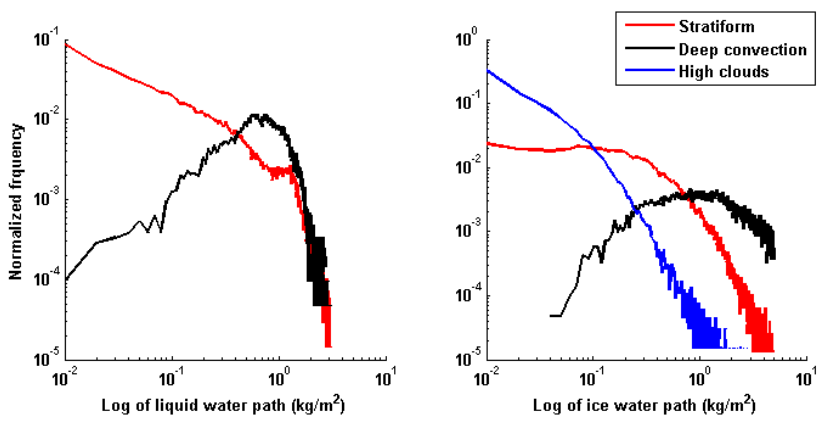

Figure 5. Probability density functions of liquid and ice water paths for the selected cloud types and for the summer monsoon months (JJAS) based on CloudSat's 2B-CWC-RVOD and 2B-CLDCLASSLIDAR products.

tions are broader. The pdfs for deep convective clouds follow gamma distribution. It should be noted that CloudSat/CPR in itself cannot detect the thermodynamic phase of the hydrometeors. It relies on ancillary input from ECMWF (temperature profiles) and MODIS to partition total cloud condensate into ice and liquid fractions by linearly scaling them between -20 and $0^{\circ} \mathrm{C}$. This introduces some uncertainty in the estimates of liquid and ice water paths (Devasthale and Thomas, 2012). 


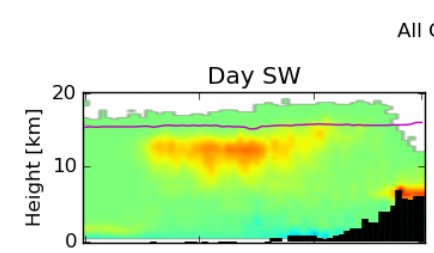

All Clouds
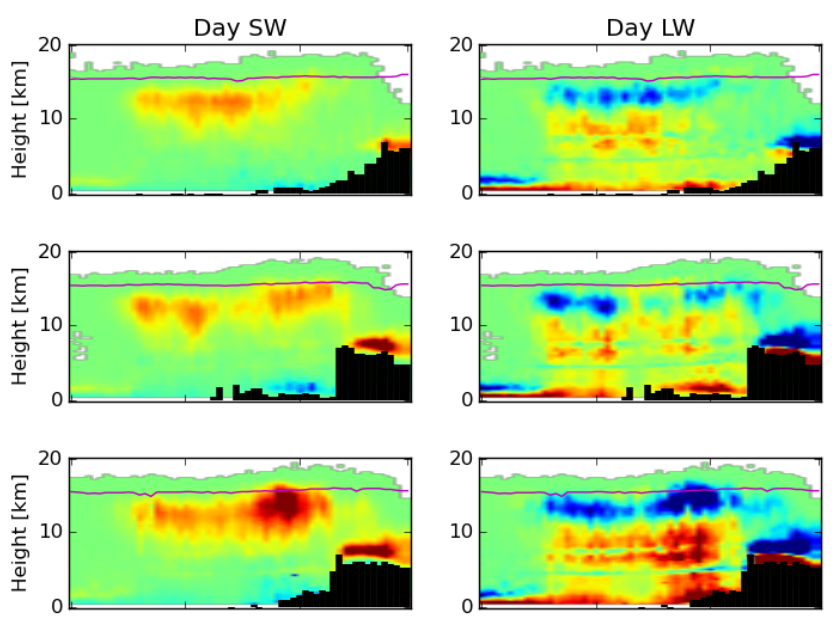

$-0.5$ $0.5[K / d]$

Figure 6. The vertical structure of CRH partitioned into its SW and LW components. All cloud types are included in the analysis and the data from 2006-2010 for the months June-September are used. The magenta-coloured lines show the level of zero net clear-sky radiative heating $(\mathrm{LZRH})$.

\subsection{CRH during the monsoon}

Figure 6 provides an overview of daytime CRH separated into its shortwave (SW) and longwave (LW) components averaged over the core monsoon season (i.e. June through September). We observe noticeable differences in the CRH magnitude and spatial distribution in the three selected zones. For example, the vertical gradient in the SW heating in the uppermost troposphere north of the equator steepens from $\mathrm{Z} 1$ to $\mathrm{Z} 3$. The seasonally averaged SW heating with values exceeding $0.25 \mathrm{~K} \mathrm{day}^{-1}$ remains mainly near the equatorial regions in $\mathrm{Z} 1$ and gradually extends towards northerly regions in $\mathrm{Z} 2$ and $\mathrm{Z3}$. The $\mathrm{SW}$ heating follows to a large extent the vertical distribution of cloud fraction (cf. Fig. 4) with the highest values (of the order of $0.5 \mathrm{~K} \mathrm{day}^{-1}$ ) found over $\mathrm{Z3}$ at $15-20^{\circ} \mathrm{N}$ and $12-16 \mathrm{~km}$ altitude. In general, the SW heating takes place in the upper troposphere below the LZRH (except possibly over $\mathrm{Z} 3$ around $20^{\circ} \mathrm{N}$ ). One noticeable exception is the Tibetan Plateau, where the heating takes place below $10 \mathrm{~km}$ and is of similar magnitude in $\mathrm{Z} 2$ and $\mathrm{Z3}$. As a seasonal average, the upper troposphere predominantly experiences cloud radiative cooling in the LW component. The LW cooling mainly takes place in the upper troposphere, below the LZRH, and is highest in Z3, over the Bay of Bengal and the southern slopes of the Himalayas, mainly as a result of cooling from the tops of stratiform and convective clouds (cf. Figs. S5 and S6). Over the Tibetan Plateau, the high frequency of stratiform clouds gives rise to a cooling, in particular over Z2 and Z3. A narrow band of longwave cooling at the freezing height (between 4.5 and $5.5 \mathrm{~km}$ ) is due to the ef-

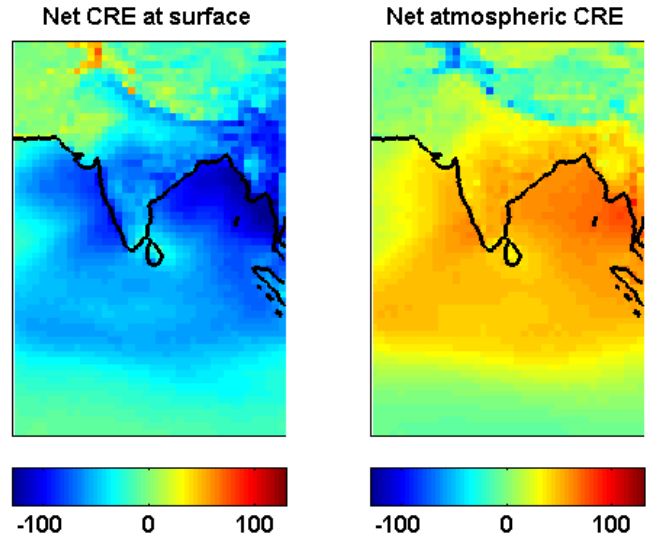

Figure 7. The net cloud radiative effect (in $\mathrm{W} \mathrm{m}^{-2}$ ) at surface and in the atmosphere based on CERES data averaged over the summer monsoon months (JJAS).

fect of melting layer. This effect is most visible in $\mathrm{Z} 2$ and Z3, extending meridionally over the entire cross section. The LW cooling pattern is in general patchier than the SW warming pattern, and in some parts of the troposphere clouds actually generate an overall LW heating during the monsoon period. The Figs. S4-S6 present individual contribution of high clouds, deep convection and combined alto- and nimbostratus clouds to the total SW and LW heating rates separately. The observed patchiness in the LW component in the upper troposphere can be explained by opposing heating and cooling effects from different cloud categories at different levels. For example, the high cloud category, containing thin cirrus with low ice water content, generally warms the upper troposphere between 10 and $15 \mathrm{~km}$. On the other hand, deep convective clouds and stratiform clouds, with higher water contents than cirrus, cool the atmosphere in the same layer. The net result then depends on the local frequency of occurrences of these two cloud types and can be noisy due to the short time period.

The climatological cloud fraction (Fig. 4), cloud water path (Fig. 5) and CRH discussed above lead to a net cooling at the surface when averaged over all cloud types and summer months (Fig. 7, JJAS). The atmosphere is, on the other hand, warmed considerably due to cloud radiative effects. Cloud radiative effects from the Clouds and Earth's Radiant Energy System (CERES, EBAF-TOA and EBAF-Surface) sensor onboard NASA's Earth Observing Satellites for the summer months from 2006 through 2011 are presented in Fig. 7 (CERES data are used here to illustrate spatial patterns due to their better spatial sampling relative to CloudSat and CALIPSO). It is to be noted that both the surface cooling and atmospheric warming are strongest over those regions where the frequency of deep convective clouds and optically thick stratiform clouds is also high. 


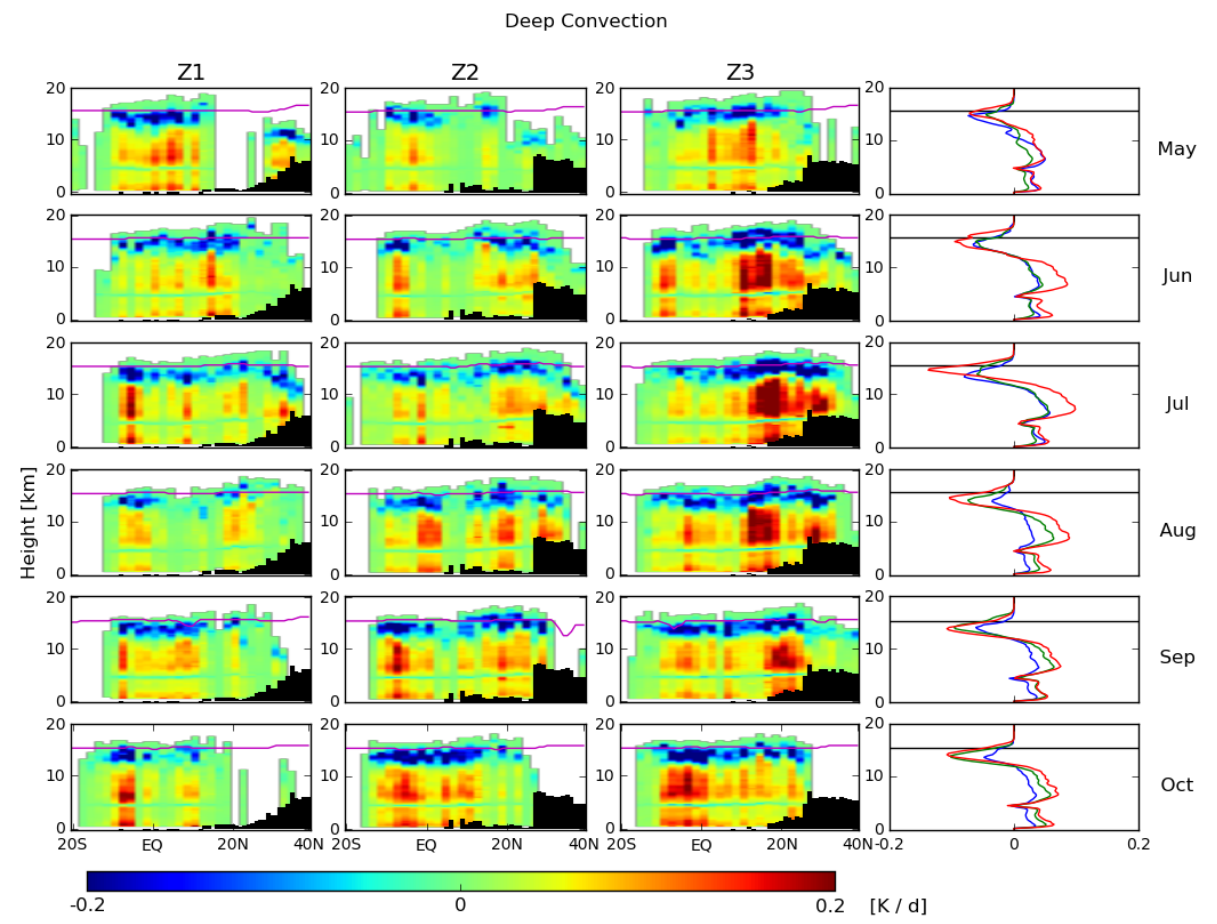

Figure 8. The monthly evolution of $\mathrm{CRH}$ due to deep convective clouds. The magenta-coloured lines show the level of zero net clear-sky radiative heating $(\mathrm{LZRH})$.

\subsection{Monthly evolution of CRH}

The radiative heating in the troposphere over the Indian subcontinent is mainly driven by water vapour and aerosols during pre-monsoon phases. Apart from local anthropogenic sources, transport of dust, sea-salt and other natural aerosols from the Indian Ocean and Arabian Peninsula contributes to the total aerosol load over the subcontinent once the direction of winds becomes westerly or southwesterly in May. The land-sea thermal contrast further draws in moisture over the land from the neighbouring seas and sets the stage for rainfall onset. Given the distinct monthly variability in cloud fraction from pre- to post monsoon, examining corresponding monthly variations of $\mathrm{CRH}$ provides interesting insights that can be directly evaluated in the global climate models. Although convective cores contribute considerably to the total rainfall, the absolute fraction of these cores is usually very low. Other cloud types, such as outflow anvils produced during the life cycle of a typical convective system, and stratiform clouds stay longer in the atmosphere, and could thus have a higher radiative impact over time. Therefore, we investigated the temporal evolution of the individual contribution of the different cloud types to CRH by taking into account their absolute fraction.

Figure 8 shows the monthly evolution of total $(\mathrm{LW}+\mathrm{SW})$ $\mathrm{CRH}$ for deep convective clouds. Among the different cloud types studied here, the systematic monthly meridional progression of CRH is most clearly visible for these clouds.
The convective cores warm nearly the entire troposphere enhancing latent heat release and extending it vertically in the column, in some areas from $1 \mathrm{~km}$ to up to $14 \mathrm{~km}$, but also cause strong net cooling at cloud top in the uppermost troposphere. In Z1, the convective contribution to CRH is limited to the equatorial region in May and it is not until August that the highest $\mathrm{CRH}$ over land (around $30^{\circ} \mathrm{N}$ ) is observed when both the easterly branch of monsoonal circulation from north-central India and the westerly branch from the Arabian Sea provide conducive conditions for deep convection. For all regions, the cooling due to convective cores extends above the base of the TTL, in particular over Z2 and Z3 from June to August between 10 and $20^{\circ} \mathrm{N}$. This result is in agreement with previous observations by Zipser et al. (2006), who used data from the Tropical Rainfall Measurement Mission (TRMM) to show that the most intense thunderstorms (essentially caused by these convective cores) in the world occur over this region. Previous studies also report the Bay of Bengal and southern foothills of Himalayas supporting environments conducive for the penetrative convection during summer monsoon (James et al., 2008; Devasthale and Fueglistaler, 2010). Figure 8 clearly supports these previous results.

The monthly total CRH due to alto- and nimbostratus clouds is shown in Fig. 9. In June-August, very distinct warming (values exceeding $0.2 \mathrm{~K} \mathrm{day}^{-1}$ in average after normalizing with cloud fraction) in the middle troposphere (4$9 \mathrm{~km}$ ) and equally strong cooling in the upper troposphere 


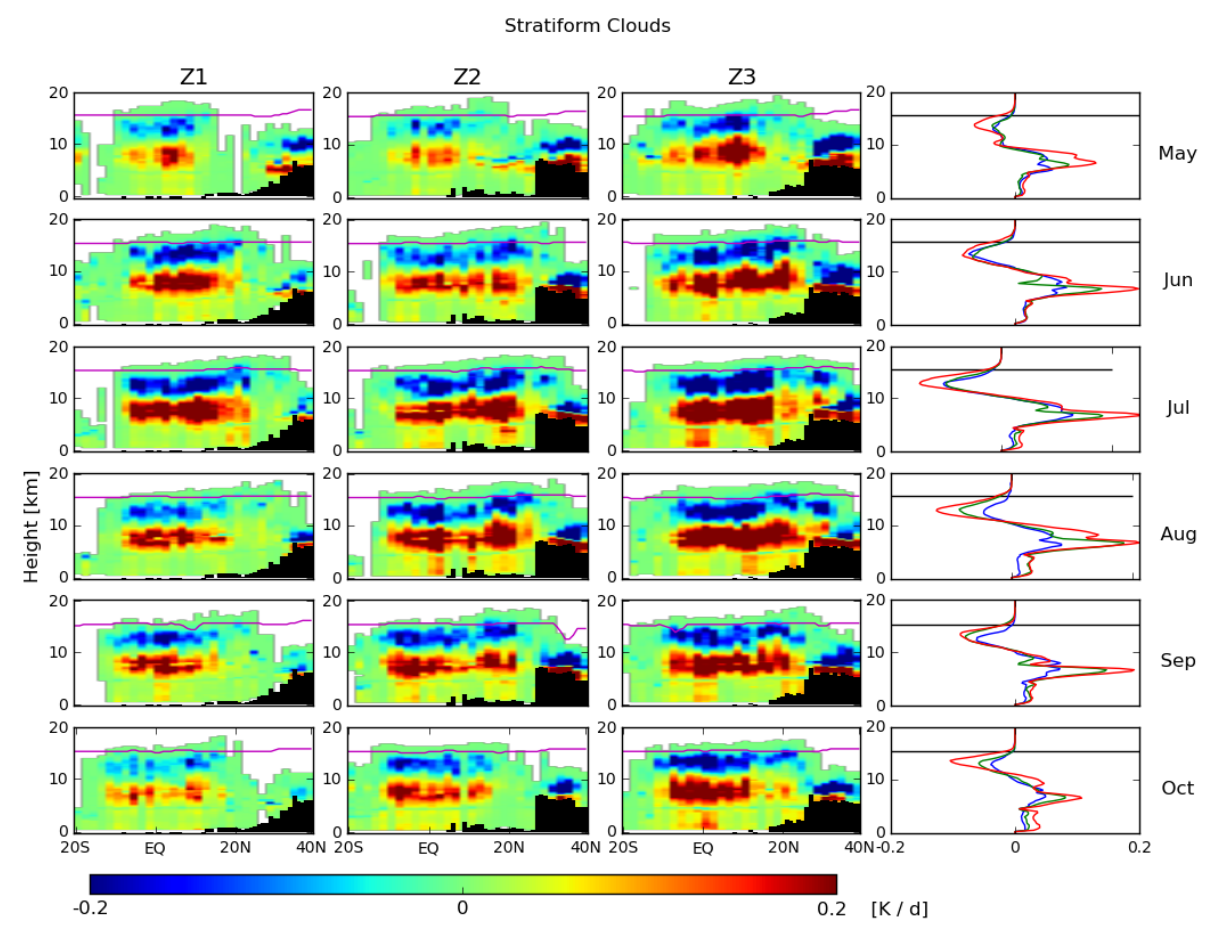

Figure 9. The monthly evolution of CRH due to alto- and nimbostratus clouds.

(between $9 \mathrm{~km}$ and LZRH) are observed in all regions. In August, the cooling at the top is partly offset by warming, mainly due to high vertical variability of these clouds in this particular month caused by the late advection of the eastern branch of the monsoon in the upper troposphere, while the western branch triggers relatively shallow convection. The $\mathrm{CRH}$ due to these clouds is weaker in September.

High clouds, either of convective origin or the result of the large-scale vertical ascent, warm the base and interior of the TTL (Fig. 10). Irrespective of their origin, it is clear that high thin clouds play a key role in assisting the gradual large-scale vertical transport of upper tropospheric air into the stratosphere as these clouds provide the highest heating rates above the TTL (Fig. 10). Over the Arabian Sea (Fig. 10, Z1), the maximum heating of the TTL due to these clouds occurs in June, while over land the peak is in August. It is worth noting that this coincides with the highest heating by convective clouds, also observed during the month of August, thus indicating a greater control by convective processes compared to large-scale ascent in this particular month and latitude band.

Previous studies show that the latent heating over the Indian monsoon region peaks at around $7 \mathrm{~km}$ (Zuluaga et al., 2010), mainly during June to August months when monsoon is in its most active phase. Based on the vertical distribution of clouds (Figs. 4 and S1-S3) and their radiative heating profiles examined here (Figs. 8-10), it is evident that $\mathrm{CRH}$ contributes significantly to the total diabatic heating in the UTLS region, especially in the TTL. Therefore, the next section focuses specifically on quantifying CRH in the TTL.

\subsection{CRH in the TTL}

In order to gain insights into the net effect of deep convective clouds and cirrus on the TTL, the probability density functions of $\mathrm{CRH}$ for data bins that are located above the LZRH during summer monsoon months (May-August) are presented in Fig. 11. While LZRH is typically observed between 14 and $15 \mathrm{~km}$, the highest cloudy bins where CRH is reported are observed between 18 and $19 \mathrm{~km}$. All data north of the equator from the three zones are analysed to improve statistical sampling. Deep convection causes a net cooling of the TTL from May through July, but the PDFs become broader as the monsoon progresses. The largest average cooling rate is observed during July $\left(-4.20 \mathrm{~K} \mathrm{day}^{-1}\right)$ but the same month also displays the highest standard deviation $\left(3.12 \mathrm{~K} \mathrm{day}^{-1}\right)$, meaning that there are more extreme events in general and that some events actually warm the TTL. The impact of deep convective clouds on the TTL decreases rapidly in August. Previous studies (Devasthale and Grassl, 2009; Devasthale and Fueglistaler, 2010), based on optical imagers, also argued that the most intense and penetrative convective events occur during early phases of the monsoon. By August, the surface temperatures over the subcontinent are relatively low and favourable conditions for penetrative convection no longer persist.

The net effect of high clouds on the TTL is a warming during all active months of the monsoon. The mean warming effect is lowest in July when convection is most active. As evident in the PDF, this is because some of the high clouds are 


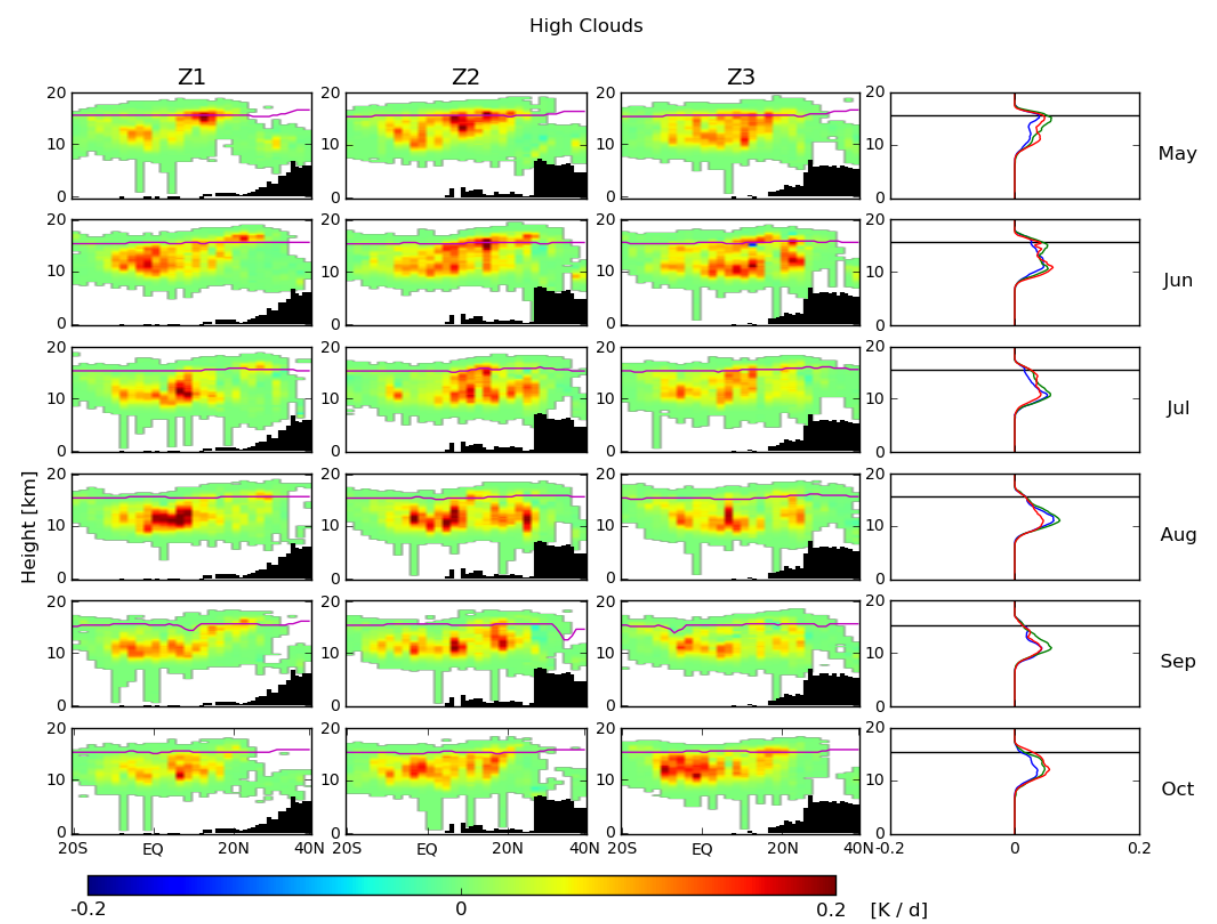

Figure 10. The monthly evolution of CRH due to high clouds.

cooling during this month. Considering that the deep convection exhibits the strongest cooling in this month, we believe that the cooling effect of high clouds may be due to remnants of deep convection (such as tops of relatively thick anvil cirrus, cirrostratus, etc.) emitting at much colder temperature and/or having higher water contents than thin or semitransparent cirrus would in other cases.

\subsection{The role of active and break periods in the UTLS region}

Intra-seasonal oscillations are one of the intrinsic characteristics of Indian summer monsoon rainfall and occur as active and break periods with no fixed periodicity. During active periods, high precipitation amounts are experienced over much of the subcontinent. These periods are usually followed by periods of reduced rainfall, called break periods. The mechanism behind these oscillations remains a topic of active research; however it is beyond doubt that they play an important role in modulating the seasonal mean rainfall distribution and amount over the subcontinent. For example, Goswami and Ajaya Mohan (2001) demonstrated that stronger than normal summer monsoon rainfall is associated with a higher frequency of active periods. Enhanced cyclonic flow and convection is often observed during active periods. Enhanced upward motion in the northern position of the ITCZ is also observed during active periods. This intraseasonal variability in rainfall (and convective clouds and associated anvils, cir- rus etc) has direct relevance for the distribution of heat and moisture within a given monsoon season.

Over the subcontinent itself, large variations in the spatial distribution of convection (and associated clouds) occur during active and break periods. Using 25 years of AVHRRbased cloud climatology, Devasthale and Grassl (2009) showed that deep convection extends far northwards and covers nearly all of northern India during active periods. Especially the deep convective activity over the Arabian Sea is enhanced during this period, while during break periods, deep convection is restricted to the Bay of Bengal, southern slopes of Himalayas and the north-eastern parts of continental India. Using the same data set, Devasthale and Fueglistaler (2010) further investigated very deep and penetrating convection into the TTL. They showed that the penetrating convection is substantially suppressed in the western parts of the subcontinent during break periods and argued that active periods, although less frequent, could have a large influence on the composition of the TTL.

Here we add a new dimension to these earlier studies by investigating the radiative effects of deep convection and high clouds during active/break periods in the UTLS region. The definition of these periods follows Rajeevan et al. (2010). Figure 12 shows the PDFs of instantaneous CRH for cloudy bins of CloudSat-CALIPSO located above $10 \mathrm{~km}$ and LZRH, respectively, observed north of the equator. $\mathrm{CRH}$ of deep convection has a mean cooling effect in absolute terms above LZRH during both active $\left(-1.23 \mathrm{~K} \mathrm{day}^{-1}\right)$ and break periods $\left(-0.36 \mathrm{~K} \mathrm{day}^{-1}\right)$. However, the active periods show much 

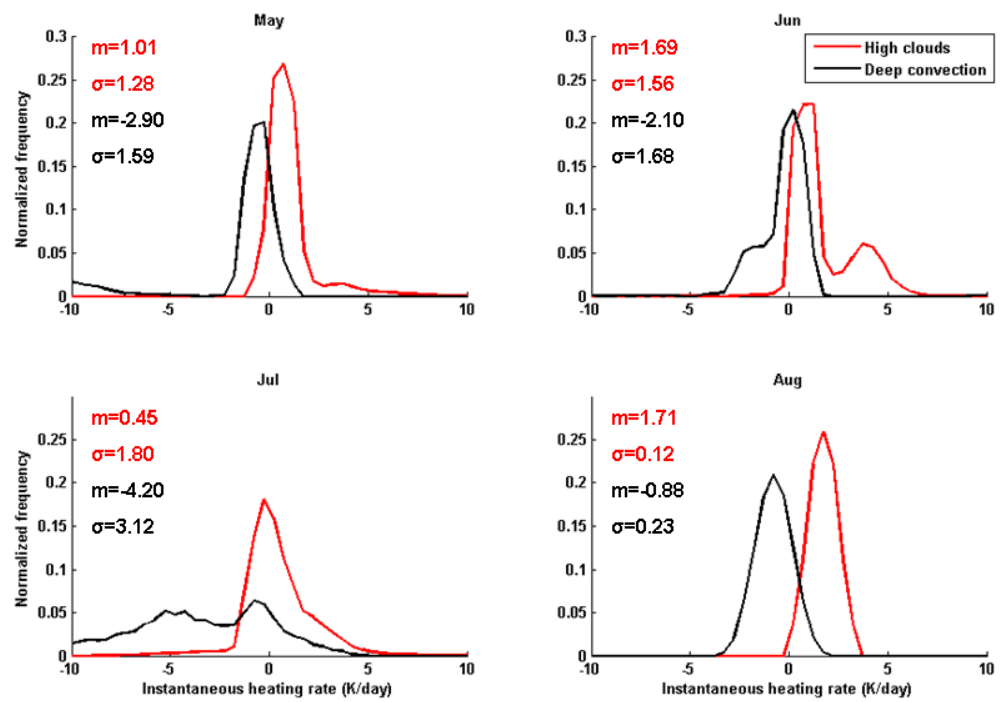

Figure 11. Probability density functions of instantaneous CRH for cloudy bins located above LZRH in all three regions (Z1-Z3) north of the equator for the years 2006-2010. The symbols $m$ and $\sigma$ denote mean and standard deviation respectively.
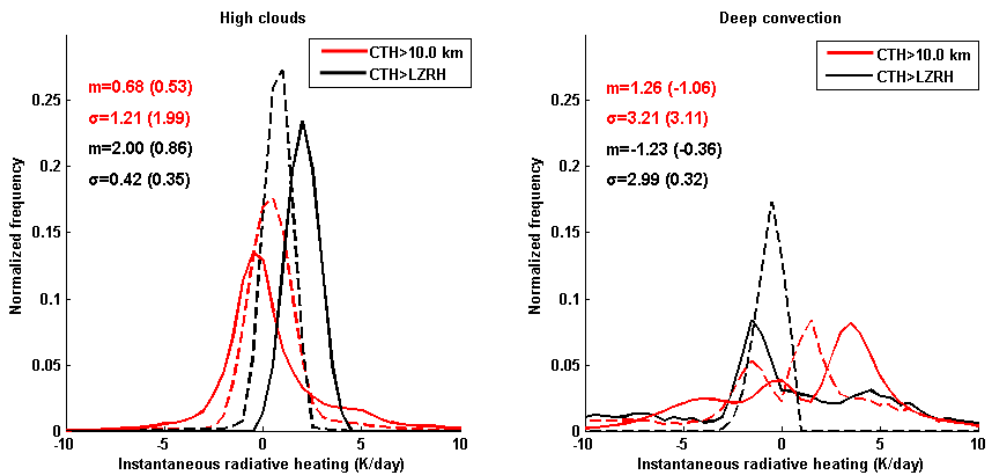

Figure 12. Probability density functions of instantaneous CRH for cloudy bins located above $10 \mathrm{~km}$ (red colour) and LZRH (black colour) during active and break periods of the monsoon. The solid lines show PDFs for active periods and dashed lines for break periods of the monsoon. The symbols $m$ and $\sigma$ denote mean and standard deviation respectively. The values in brackets are for the break periods of monsoon.

wider PDFs of CRH, in particular on the warming side of the distribution, suggesting that $\mathrm{CRH}$ of deep convection could affect the TTL very differently during active periods, compared to break periods. If the upper troposphere is also included in the analysis (i.e. cloud tops $>10 \mathrm{~km}$ ), deep convection produces an even stronger warming during active periods compared to breaks (and the PDF is still broader). This is due to the fact that convection is more widespread in general and penetrates deeper during active periods.

For high clouds, the mean radiative warming effect above LZRH is more than twice as large during active periods, compared to break periods. After including high clouds with tops located higher than $10 \mathrm{~km}$, the warming during active periods is still larger than that observed during break periods, albeit not as strong.

\subsection{Cloud radiative effects at the surface and in the atmosphere}

Considering the ubiquity of clouds during monsoon months and their radiative heating/cooling potential in the atmosphere discussed in Sects. 3.1-3.5, clouds may also impact the radiative heating of the surface. One way to evaluate the resulting cloud impact on the surface is to investigate net cloud radiative effect (CRE) (expressed in $\mathrm{W} \mathrm{m}^{-2}$ ). This metric is commonly used in energy budget studies and to evaluate climate models and will provide insights into the role of different cloud types in acting as a potential "regulator" of monsoonal circulation by modulating spatial and vertical thermal contrast.

Table 1 summarizes mean diurnally averaged CRE values and associated standard deviations for different cloud 
Table 1. Area-averaged (northwards of the Equator) cloud radiative effect (CRE) and its standard deviation (in brackets) of three selected cloud types. The months of JJAS are selected for analysis. All values are in $\mathrm{W} \mathrm{m}^{-2}$.

\begin{tabular}{lrrr}
\hline & $\begin{array}{r}\text { High } \\
\text { clouds }\end{array}$ & Stratiform & $\begin{array}{r}\text { Deep } \\
\text { convection }\end{array}$ \\
\hline \multicolumn{2}{l}{ Atmosphere } \\
\hline Z1 & $39(40)$ & $44(45)$ & $101(18)$ \\
Z2 & $45(46)$ & $45(43)$ & $132(25)$ \\
Z3 & $49(49)$ & $48(47)$ & $152(32)$ \\
\hline \multicolumn{3}{l}{ Surface } \\
\hline Z1 & $-10(36)$ & $-133(168)$ & $-391(157)$ \\
Z2 & $-13(55)$ & $-93(162)$ & $-410(157)$ \\
$Z 3$ & $-11(53)$ & $-114(181)$ & $-536(144)$ \\
\hline
\end{tabular}

Table 2. Diurnally averaged cloud radiative effect (CRE) and its standard deviation (in brackets) of three selected cloud types averaged over all three zones northwards of the Equator. The months of JJAS are selected for analysis. All values are in $\mathrm{W} \mathrm{m}^{-2}$.

\begin{tabular}{lrrr}
\hline & $\begin{array}{r}\text { High } \\
\text { clouds }\end{array}$ & Stratiform & $\begin{array}{r}\text { Deep } \\
\text { convection }\end{array}$ \\
\hline \multicolumn{2}{l}{ Atmosphere } & & \\
\hline Active & $54(49)$ & $79(57)$ & $172(38)$ \\
Break & $43(47)$ & $108(58)$ & $178(33)$ \\
\hline Surface & & & \\
\hline Active & $-29(51)$ & $-155(163)$ & $-508(164)$ \\
Break & $-25(47)$ & $-180(179)$ & $-454(135)$ \\
\hline
\end{tabular}

types over selected zones, both at the surface and in the atmosphere. It can be seen that clouds strongly cool the surface in all three zones for all cloud types. For stratiform and deep convective clouds, CREs vary considerably in the three zones, while the net impact of high clouds is similar. The deep convective clouds have a strong negative forcing at the surface which increases from Z1 to Z3. This is in agreement with the increasing fraction of these clouds from $\mathrm{Z} 1$ to $\mathrm{Z3}$ and with increasing cloud condensate. Furthermore, it agrees with the spatial pattern of net CRE at surface obtained from the CERES data, wherein the strongest cooling is observed in regions with higher fraction of deep convective clouds. The stratiform clouds also cause strong surface cooling, albeit not as strong as deep convection. Table 1 further shows that the net CRE leads to substantial atmospheric warming that is highest in the case of deep convective clouds and follows the same increasing tendency from $\mathrm{Z} 1$ to $\mathrm{Z3}$.

High values of standard deviations in all cases indicate that a large variability exists in the net impact of clouds on the atmosphere and at the surface. One of the reasons behind such high standard deviation values could be variations in micro-

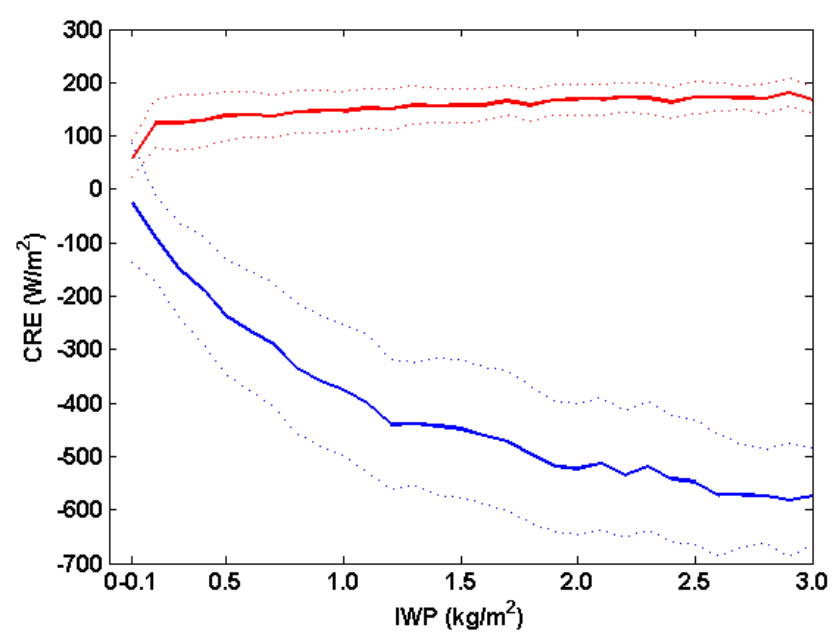

Figure 13. CRE at surface (blue lines) and in the atmosphere (red lines) as a function of ice water path. The dotted lines show standard deviation in each case. The statistics are compiled for the JJAS months over the entire study area northward of the equator.

physical properties for a particular cloud type. This aspect is further investigated by examining the relationship between CREs and ice water path as ice phase clouds are predominant over the study area and the focus of the present study is on the upper troposphere and lower stratosphere region, where these clouds are prevalent. Figure 13 shows the results for the entire study area for JJAS. Mean CREs and their standard deviations (in dotted lines) for daytime conditions are shown for the atmosphere and the surface. High clouds with low ice water path $\left(<0.1 \mathrm{~kg} \mathrm{~m}^{-2}\right)$ produce CRE in the order of $\pm 100 \mathrm{~W} \mathrm{~m}^{-2}$ at the surface, however, the cooling tendency becomes stronger as the total ice condensate increases with CREs reaching -500 to $-700 \mathrm{~W} \mathrm{~m}^{-2}$ at the surface when ice water path values reach $3.0 \mathrm{~kg} \mathrm{~m}^{-2}$. The atmosphere is consistently warmed irrespective of the value of ice water path as ice crystals absorb radiation throughout the cloudy layers.

Table 2 further shows the diurnally averaged CRE during active and break conditions of monsoon averaged over all three zones north of the equator. Note that CRE values in both Tables 1 and 2 are averaged over only cloudy pixels and not normalized by the corresponding cloud type fractions. Thus, they represent the radiative impact of individual cloud types on the surface and in the atmosphere. The frequency of occurrence of both deep convective and stratiform clouds is higher during active periods, especially in $\mathrm{Z} 1$ and $\mathrm{Z} 2$ compared to break periods (Figs. S7 and S8). The stratiform clouds are more widespread than deep convective clouds during active phases. This is in agreement with previous studies that use passive imager and TRMM data sets (Stano et al., 2002; Basanta Samala and Krishnan, 2007; Houze et al., 2007; Devasthale and Grassl, 2009; Devasthale and Fueglistaler, 2010; Dey Choudhury and Krishnan, 2011; Krishnan et al., 2011; Romatschke and Houze Jr., 
2011). The average cooling effect of stratiform and deep convective clouds at the surface is in the order of -155 and $-508 \mathrm{~W} \mathrm{~m}^{-2}$, respectively, during active periods. However, as the deep convection is generally suppressed during break periods, the importance of stratiform clouds further increases, especially in Z3 over continental India. When stratiform clouds are formed after intense surface warming during pre-break periods, they are more vigorous, deeper and optically thicker, thus causing more cooling compared to active conditions (as reflected in Table 2).

It is to be noted that occasionally some of the most intense thunderstorms occur during break periods. The build up of moist energy and very warm surface temperatures due to increased insolation at surface especially along the southern foothills of Himalayas lead to vigorous thunderstorms (Vellore et al., 2014). Although the instantaneous CRE of such deep convective events could be very high, the net CRE is also very low when averaged over the month and the wider area, due to their very low frequency.

\section{Conclusions}

Clouds are intrinsically tied to the atmospheric circulation and radiation budget. The focus of the present study has been on understanding the vertical structure of cloud radiative heating/cooling and radiative influence of clouds on the different parts of the atmosphere and the surface during the Indian summer monsoon. This has been a key knowledge gap so far. Together with previous studies on the latent heating effects of clouds, such quantification would help in understanding how clouds may interact with the monsoonal circulation.

The vertical structure of CRH follows the northward migration and withdrawal of the monsoon from May to October over the subcontinent. It was found that alto- and nimbostratus clouds intensely warm the middle troposphere and equally strongly cool the upper troposphere. Even after weighing by their vertical fraction, their warming/cooling consistently exceeds $\pm 0.2 \mathrm{~K} \mathrm{day}^{-1}$ in monthly mean composites throughout the middle and upper troposphere, respectively, and their largest impact is observed in June, July and August. In contrast, high clouds representing thin cirrus, cirrostratus, cirrocumulus, etc., dominate the total cloud fraction and cause a considerable warming in the upper troposphere, with values between $0.1-0.2 \mathrm{~K} \mathrm{day}^{-1}$ around the base of the TTL. Their largest impact is seen during the early phases of monsoon (May-July). Deep convective towers warm nearly the entire troposphere, but have a net cooling effect at the base of the TTL. While individual convective cores may produce extreme heating, their occurrence is very low and thus the net effect is smaller than that of alto- and nimbostratus and high clouds.

The net radiative impact of high clouds and deep convection on the TTL was also investigated revealing that during the monsoon, deep convection generally causes strong instantaneous cooling inside the TTL and the intensity of cooling increases with the monthly progress of the monsoon until July when the strongest cooling is observed (mean $-4.2 \mathrm{~K} \mathrm{day}^{-1}$ ). However, the PDFs of CRH also become broader as the monsoon progresses and during July such that some clouds classified as deep convection radiatively heat the TTL. High clouds, on the other hand, generally lead to a net warming effect. Deep convection has mean cooling effect in absolute terms above LZRH during both active $\left(-1.23 \mathrm{~K} \mathrm{day}^{-1}\right)$ and break periods $\left(-0.36 \mathrm{~K} \mathrm{day}^{-1}\right)$. However, the active conditions show much wider PDFs of CRH, suggesting that convective clouds do not always cool the TTL. In case of high clouds, the net warming effect above LZRH is more than double in magnitude during active conditions compared to break periods. These results highlight the increasing importance of CRH in the UTLS region as the contribution of latent heating in the total diabatic heating decreases with increasing altitude. The present study also underscores the importance of Bay of Bengal and the foothills of Himalayas in supporting the deep and penetrative convection and its remnants.

Finally, it is shown that the stratiform clouds and deep convection significantly cool the surface with a net radiative effect around -100 and $-400 \mathrm{~W} \mathrm{~m}^{-2}$, respectively. The high clouds also have a cooling radiative effect at the surface, albeit smaller than other cloud types. The atmospheric warming purely due to radiative effects of clouds is also very high, in the order of 40 and $150 \mathrm{~W} \mathrm{~m}^{-2}$ in case of stratiform and deep convective clouds respectively. The magnitude of radiative effects of convective and stratiform clouds increases from the western to eastern parts of the subcontinent. While the deep convection and stratiform clouds produce strong cooling at the surface during active periods of monsoon, the importance of stratiform clouds increases further during break periods.

\section{The Supplement related to this article is available online at doi:10.5194/acp-15-11557-2015-supplement.}

Acknowledgements. E. Johansson and A. Devasthale would like to acknowledge funding from the Swedish National Space Board (SNSB) (contract Dnr: 84/11:1 and 84/11:2). CloudSat Data Processing Center (DPC) and Science Teams are further acknowledged for providing CloudSat data sets.

Edited by: T. Garrett 


\section{References}

Basanta Samala, K. and Krishnan, R.: Cloud-radiative impacts over the tropical Indian Ocean associated with the evolution of "monsoon breaks", Int. J. Climatol., 28, 205-217, doi:10.1002/joc.1518, 2007.

D'Almeida, G. A., Koepke, P., and Shettle, E. P.: Atmospheric Aerosols: Global Climatology and Radiative Characteristics, A. Deepak, Hampton VA, USA, 561 pp., 1991.

Dessler, A. E. and Sherwood, S. C.: Effect of convection on the summertime extratropical lower stratosphere, J. Geophys. Res., 109, D23301, doi:10.1029/2004JD005209, 2004.

Devasthale, A. and Fueglistaler, S.: A climatological perspective of deep convection penetrating the TTL during the Indian summer monsoon from the AVHRR and MODIS instruments, Atmos. Chem. Phys., 10, 4573-4582, doi:10.5194/acp-10-45732010, 2010.

Devasthale, A. and Grassl, H.: A daytime climatological distribution of high opaque ice cloud classes over the Indian summer monsoon region observed from 25-year AVHRR data, Atmos. Chem. Phys., 9, 4185-4196, doi:10.5194/acp-9-4185-2009, 2009.

Devasthale, A. and Thomas, M. A.: Sensitivity of Cloud Liquid Water Content Estimates to the Temperature-Dependent Thermodynamic Phase: A Global Study Using CloudSat Data, J. Climate, 25, 7297-7307, doi:10.1175/JCLI-D-11-00521.1, 2012.

Dey Choudhury, A. and Krishnan, R.: Dynamical response of the South Asian monsoon trough to latent heating from stratiform and convective precipitation, J. Atmos. Sci., 68, 1347-1363, 2011.

Feldman, D. R., L'Ecuyer, T. S., Liou, K. N., and Yung, Y. L.: Remote sensing of tropical tropopause layer radiation balance using A-Train measurements, J. Geophys. Res., 113, D11118, doi:10.1029/2007JD009041, 2008.

Fueglistaler, S. and Fu, Q.: Impact of clouds on radiative heating rates in the tropical lower stratosphere, J. Geophys. Res., 111, D23202, doi:10.1029/2006JD007273, 2006.

Fueglistaler, S., Dessler, A. E., Dunkerton, T. J., Folkins, I., Fu, Q., and Mote, P. W.: Tropical tropopause layer, Rev. Geophys., 47, RG1004, doi:10.1029/2008RG000267, 2009a.

Fueglistaler, S., Legras, B., Beljaars, A., Morcrette, J.-J., Simmons, A., Tompkins, A. M., and Uppala, S.: The diabatic heat budget of the upper troposphere and lower/mid stratosphere in ECMWF reanalyses, Q. J. Roy. Meteor. Soc., 135, 21-37, doi:10.1002/qj.361, 2009b.

Gettelman, A., Salby, M. L., and Sassi, F.: Distribution and influence of convection in the tropical tropopause region, J. Geophys. Res., 107, 4080, doi:10.1029/2001JD001048, 2002.

Goswami, B. N. and Ajaya Mohan, R. S.: Intraseasonal oscillations and interannual variability of the Indian summer monsoon, J. Climate, 14, 1180-1198, 2001.

Haynes, J. M., Vonder Haar, T. H., L'Ecuyer, T., and Henderson, D.: Radiative heating characteristics of Earth's cloudy atmosphere from vertically resolved active sensors, Geophys. Res. Lett., 40, 624-630, doi:10.1002/grl.50145, 2013.

Henderson, D. S., L'Ecuyer, T., Vane, D., Stephens, G., and Reinke, D.: Level 2B Fluxes and Heating Rates and Level 2B Fluxes and Heating Rates with Lidar Process Description and Interface Control Document, JPL/NASA, pp. 1-28, November 2011.
Henderson, D. S., L'Ecuyer, T., Stephens, G., Partain, P., and Sekiguchi, M.: A multi-sensor perspective on the radiative impacts of clouds and aerosols, J. Appl. Meteorol. Clim., 52, 852870, 2013.

Houze, R. A., Wilton, D. C., and Smull, B. F.: Monsoon convection in the Himalayan region as seen by the TRMM Precipitation Radar, Q. J. Roy. Meteorol. Soc., 133, 1389-1411, 2007.

Huffman, G. J., Adler, R. F., Bolvin, D. T., and Gu, G.: Improving the global precipitation record: GPCP Version 2.1, Geophys. Res. Lett., 36, L17808, doi:10.1029/2009GL040000, 2009.

Krishnan, R., Ayantika, D. C., Kumar, V., and Pokhrel, S.: The long-lived monsoon depressions of 2006 and their linkage with the Indian Ocean Dipole, Int. J. Climatol., 31, 1334-1352, doi:10.1002/joc.2156, 2011.

L'Ecuyer, T. S. and Jiang, J.: Touring the Atmosphere Aboard the A-Train, Phys. Today, 63, 36-41, 2010.

L'Ecuyer, T. S. and McGarragh, G.: A ten year climatology of atmospheric radiative heating and its vertical structure from TRMM observations, J. Climate, 23, 519-541, 2010.

L'Ecuyer, T. S., Wood, N., Haladay, T., and Stephens, G. L.: The impact of clouds on atmospheric heating based on the R04 CloudSat fluxes and heating rate detest, J. Geophys. Res., 113, D00A15, doi:10.1029/2008JD009951, 2008.

Ling, J. and Zhang, C.: Diabatic heating profiles in recent global reanalyses, J. Climate, 26, 3307-3325, doi:10.1175/JCLI-D-1200384.1, 2013.

Mace, G. G., Zhang, Q., Vaughan, M., Marchand, R., Stephens, G., Trepte, C., and Winker, D.: A description of hydrometeor layer occurrence statistics derived from the first year of merged Cloudsat and CALIPSO data, J. Geophys. Res., 114, D00A26, doi:10.1029/2007JD009755, 2008.

McFarlane, S. A., Mather, J. H., and Ackerman, T. P.: Analysis of tropical radiative heating profiles: A comparison of models and observations, J. Geophys. Res., 112, D14218, doi:10.1029/2006JD008290, 2007.

Rajeevan, M., Gadgil, S., and Bhate, J.: Active and break spells of the Indian summer monsoon, J. Earth Syst. Sci., 119, 229-247, 2010.

Randel, W. J. and Jensen, E. J.: Physical processes in the tropical tropopause layer and their role in a changing climate, Nat. Geosci., 6, 169-176, doi:10.1038/ngeo1733, 2013.

Romatschke, U. and Houze Jr., R. A.: Characteristics of precipitating convective systems in the South Asian monsoon, J. Hydrometeorol., 12, 3-26, 2011.

Rossow, W. B. and Pearl, C.: 22-year survey of tropical convection penetrating into the lower stratosphere, Geophys. Res. Lett., 34, L04803, doi:10.1029/2006GL028635, 2007.

Sherwood, S. C., Bony, S., and Dufresne, J.-L.: Spread in model climate sensitivity traced to atmospheric convective mixing, Nature, 505, 37-42, 2014.

Stano, G., Krishnamurti, T. N., Vijaya Kumar, T. S. V., and Chakraborty, A.: Hydrometeor structure of a composite monsoon depression using the TRMM radar, Tellus A, 54, 370-381, 2002.

Stubenrauch, C. J., Rossow, W. B., Kinne, S., Ackerman, S., Cesana, G., Chepfer, H., Di Girolamo, L., Getzewich, B., Guignard, A., Heidinger, A., Maddux, B., Menzel, P., Minnis, P., Pearl, C., Platnick, S., Poulsen, C., Riedi, J., Sun-Mack, S., Walther, A., Winker, D., Zeng, S., and Zhao, G.: Assessment of global cloud datasets from satellites: Project and Database initiated by 
the GEWEX Radiation Panel, B. Am. Meteorol. Soc., 94, 10311049, doi:10.1175/BAMS-D-12-00117.1, 2012.

Tzella, A. and Legras, B.: A Lagrangian view of convective sources for transport of air across the Tropical Tropopause Layer: distribution, times and the radiative influence of clouds, Atmos. Chem. Phys., 11, 12517-12534, doi:10.5194/acp-11-12517-2011, 2011.

Vellore, R., Krishnan, R., Choudhury, A., Pendharkar, J., and Sabin, T.: On anomalous precipitation enhancement over the foothills of the Himalayas during break monsoons, Clim. Dynam., 43, 20092031, doi:10.1007/s00382-013-2024-1, 2014.

Wang, Z., Vane, D., Stephens, G., and Reinke, D.: Level 2 Combined Radar and Lidar Cloud Scenario Classification Product Process Description and Interface Control Document Version 1.0, JPL/CalTech, NASA, Pasadena, USA, 1-61, 2013.

Webster, P. J., Magana, V. O., Palmer, T. N., Shukla, J., Tomas, R. A., Yanai, M., and Yasunari, T.: Monsoons: Processes, predictability, and the prospects for prediction, J. Geophys. Res., 103, 14451-14510, 1998.
WCP-55: Report of the expert meeting on aerosols and their climate effects, World Meteorological Organization, Geneva, 107 pp., 1983.

Wright, J. S. and Fueglistaler, S.: Large differences in reanalyses of diabatic heating in the tropical upper troposphere and lower stratosphere, Atmos. Chem. Phys., 13, 9565-9576, doi:10.5194/acp-13-9565-2013, 2013.

Yang, Q., Fu, Q., and Hu, Y.: Radiative impacts of clouds in the tropical tropopause layer, J. Geophys. Res., 115, D00H12, doi:10.1029/2009JD012393, 2010.

Zipser, E. J., Cecil, D., Liu, C., Nesbitt, S., and Yorty, D.: Where are the most intense thunderstorms on earth?, B. Am. Meteorol. Soc., 87, 1057-1071, 2006.

Zuluaga, M. D., Hoyos, C. D., and Peter, J.: Webster, Spatial and Temporal Distribution of Latent Heating in the South Asian Monsoon Region, J. Climate, 23, 2010-2029, doi:10.1175/2009JCLI3026.1, 2010. 